\title{
Call for Chapters: Broadband Wireless Access Networks for 4G: Theory, Application, and Experimentation
}

\author{
http://www.igi-global.com/publish/call-for-papers/call-details/751
}

\section{Editors}

Raúl Aquino (University of Colima, Mexico)

Arthur Edwards (University of Colima, Mexico)

Víctor Rangel (National Autonomous University of Mexico, Mexico)

\section{Deadlines}

Proposals Submission Deadline: February 15, 2013

Full Chapters Due: April 15, 2013

Submission Date: July 30, 2013

\section{Introduction}

Broadband Wireless Access (BWA) networks will revolutionize the way wireless communication is used today for the transmission of mobile, nomadic, and fixed digital applications, and services for the next generation of cellular systems. Global trends indicate that Long Term Evolution LTE (release 8), LTE-Advanced (release 10) and IEEE 802.16-m will emerge as new technologies to provide very high data rates above $300 \mathrm{Mbps}$, or even exceed $1 \mathrm{Gbps}$ in LTE-Advanced. These new systems are the best BWA technologies that will support the increased demand of fourth generation $(4 \mathrm{G})$ traffic, which will include a larger number of subscribers and active simultaneous requested services per a mobile user such as video conferencing and video streaming applications using a very large radio bandwidth.

International Mobile Telecommunications-Advanced (IMT-Advanced) or 4G are mobile systems that extend and improve upon the capabilities of the IMT-2000 family of standards. These systems are expected to provide users with access to a variety of advanced IP-based services and applications, supported by mobile and fixed broadband packet-based networks. The IMT-Advanced systems can support a wide range of data rates, with different quality of service $(\mathrm{QoS})$ requirements, proportional to user mobility conditions in multi-user environments. According to the IMTAdvanced, only LTE-Advanced and IEEE 802.16-m fulfill the complete set of requirements for $4 \mathrm{G}$.

\section{Objective of the Book}

The book we propose will present a state-of-the-art overview of the recent developments in the area of broadband wireless access networks, including mobile standards LTE (release 8), LTE-Advanced, and IEEE $802.16 \mathrm{~m}$. Because of these standards as a system needs to take many features into consideration due to optimizations at each level which involve lots of complexity and challenging implementation. Numerous changes in lower layers (PHY ad MAC) can be expected to support larger bandwidths with more flexible allocations and to make use of further enhanced antenna technologies, coordinated base stations, scheduling, MIMO, 
interference management, and suppression will also require changes in the network architecture. Recently, relaying is being studied as an enhancement of LTE towards LTE-Advanced, and the IEEE $802.16 \mathrm{~m}$ standard. The main objective of introducing relaying in LTE-Advanced and IEEE $802.16 \mathrm{~m}$ is to provide extended network coverage at low cost.

The consecutive chapters of this book will present topics related to the actual broadband wireless technologies that work together to carry out coordinated functions. The chapters will also present new theory and applications devoted to the improvement and development of broadband wireless access networks.

The mission of the book is to gather the knowledge and experience of enthusiastic and expert researchers who work in the area of broadband wireless access networks and transmit their knowledge and enthusiasm in a collaboration that leads to the edition of a book that will be one of the first of its kind, and a primary source of reading for students wishing to become involved in this area of research.

\section{Target Audience}

The prospective audience of the book "Broadband Wireless Access Networks for $4 G$ " will be of interest to undergraduate and graduate students interested in Broadband Wireless Access Networks theory, implementation and application, as well as professors teaching or researching this area and practitioners in the public and private sectors.

\section{Recommended topics include, but are not limited to the following:}

- LTE, LTE-Advanced and IEEE $802.16 \mathrm{~m}$ performance issues and optimizations

- LTE and IEEE 802.16-e deployment experiences, field tests and measurements, and real performance analysis

- Mobile vehicular technologies for LTE, LTE-Advanced and IEEE $802.16 \mathrm{~m}$

- End-to-End quality of service

- LTE Voice Developments

- Resource allocation management strategies and scheduling algorithms

- Relay networks, relay assisted, and cooperative communications

- MIMO, spatial multiplexing and OFDM enhanced technique

- Modulation and coding schemes

- Intra-cell coordinated multipoint (CoMP)

- Smart antennas

- Energy conservation technologies

- Propagation models

- Interference control

- Detection and estimation

- Femtocell and heterogeneous networks

\section{Submission Procedure}

Researchers and practitioners are invited to submit on or before February 15, 2013, a 2-3 page chapter proposal clearly explaining the mission and concerns of his or her proposed chapter. Authors of accepted proposals will be notified by February 20, 2013 about the status of their proposals and sent chapter guidelines. Full chapters are expected to be submitted by April 15, 2013. All submitted chapters will be reviewed on a double-blind review basis. Contributors may also be requested to serve as 
reviewers for this project.

\section{Publisher}

This book is scheduled to be published by IGI Global (formerly Idea Group Inc.), publisher of the "Information Science Reference" (formerly Idea Group Reference), "Medical Information Science Reference," "Business Science Reference," and "Engineering Science Reference" imprints. For additional information regarding the publisher, please visit www.igi-global.com. This book is anticipated to be released in 2013.

\section{Important Dates}

February 15, 2013: Proposal Submission Deadline

February 20, 2013: Notification of Acceptance

April 15, 2013: $\quad$ Full Chapter Submission

June 15, 2013: $\quad$ Review Results Returned

July 15, 2013: $\quad$ Final Chapter Submission

July 30, 2013: $\quad$ Final Deadline

\section{Editorial Advisory Board Members:}

Dr. David Covarrubias Rosales, Center for Scientific Research and Higher Education of Ensenada (CICESE), Mexico.

Dr. Abdullah Bin Gani, University of Malaya, Malaysia.

Dr. Robert M. Edwards, University of Loughborough, United Kingdom.

Dr. Arturo Serrano Santoyo, Center for Scientific Research and Higher Education of Ensenada (CICESE), Mexico.

Dr. Aldo Méndez Pérez, Autonomous University of Tamaulipas, Mexico.

Dr. Luis Armando Villaseñor González, Plantronics Inc. México.

Dr. Miguel López Guerrero, Metropolitan Autonomous University, Mexico.

Dr. Zbynek Kocur, Czech Technical University in Prague, Prague.

Dr. Lukas Vojtech, Czech Technical University in Prague, Prague.

Dr. Robert Urban, Czech Technical University in Prague, Prague.

\section{Inquiries and submissions can be forwarded electronically (Word document):}

Dr. Raúl Aquino Santos

University of Colima

Avenida Universidad 333, C. P. 28040, Colima, Colima, México

Tel.: +52-312-3161075

E-mail: aquinor@ucol.mx

http://raquino.siteldisolutions.com/ 